\title{
Financial Feasibility of Public Bike Rental Systems in Spain
}

\author{
Alfredo G. Hernández-Díaz ${ }^{\mathrm{a}, *}$, Julián Sastre ${ }^{\mathrm{b}}$, Ana D. López-Sánchez ${ }^{\mathrm{a}}$, María Cuello ${ }^{\mathrm{b}}$, Julián Molinac \\ ${ }^{a}$ Department of Economics, Quantitative Methods and Economic History, Universidad Pablo de Olavide, Seville, Spain \\ ${ }^{b}$ Consultora Alomon, Seville, Spain \\ ${ }^{c}$ Department of Applied Economics (Mathematics), Universidad de Málaga, Málaga, Spain
}

\begin{abstract}
In recent years, many public bike rental systems have proliferated in Spain. Unfortunately, many have had to close because of their poor financial feasibility. The aim of this paper is twofold. On the one hand, a benchmarking of the main public bicycle systems in Spain is conducted, analysing the growth in the last decades, with special emphasis on successful systems and on the recently failed. In addition, the financial feasibility of some successful systems in Spain is analysed: Seville, Valencia and Barcelona. Thus, major factors directly related to the viability of such systems are discussed. A proper and correct knowledge of these factors is essential when making decisions in mobility policies. The main factors on which the management company may decide are: pricing policy (annual and weekly rate), advertising rates, and system dimensions (number of docking stations, anchors and bicycles). There are other external factors not directly controlled by the company (subscribers, occupancy rate of advertising space and system maintenance cost) but which are crucial to their feasibility. To achieve the aforementioned objectives, mobility studies in Seville (1400 surveys) and Barcelona (1000 surveys) were conducted in order to achieve more accurate parameter values (time cycling, distances, used rate, frequencies, etc.). Despite the similarities between the systems in Valencia and Seville, they have shown very different profitability. The high profitability in Valencia and Barcelona is highlighted in contrast to the case of the Seville system.
\end{abstract}

Keywords: public bike-sharing system, financial feasibility, Spain, public transport policy, planning

\section{Introduction}

Today, the concern about carbon emissions, transport costs and traffic congestion has increased around the world, forcing governments to design better transport strategies and infrastructures in order to reduce pollution, health problems and fuel consumption. Most of the efforts to achieve these goals are focused on encouraging urban residents to use public transport instead of private automobiles. Several cities have set up public bicycle-sharing systems (BSS) to facilitate short trips within the city. A standard BSS consists of a network of bicycle stations where bicycles are docked and available for pick up. Licensed operators often use low prices or even free access to bicycles, for limited times. As of June 2014, public bike-sharing systems were available in 50 countries on five continents, including 712 cities, operating approximately 806, 200 10 bicycles at 37,500 stations. The countries with the highest number of systems are Spain (128), Italy (104), and China (79). As of July 2013, the systems with greater market penetration are both operating in France, the Parisian Velib' with 1 bike per 97 inhabitants and Vlo'v in Lyon with one bike per 121 residents.

Bicycle sharing increases transit use, decreases personal vehicle trips, decreases gas emissions and improves public health. DeMaio [5] stated that stated that 'as the price of fuel rises, traffic congestion worsens,

\footnotetext{
*Corresponding author. Tel.: + 34954348379

Email addresses: agarrher@upo.es (Alfredo G. Hernández-Díaz), juliansastre@juliansastre.com (Julián Sastre), adlopsan@upo.es (Ana D. López-Sánchez), maria.cuello.leon@gmail.com (María Cuello), julian.molina@uma.es (Julián Molina)
} 
populations grow, and a greater worldwide consciousness arises around climate change, it will be necessary for leaders around the world to find new modes of transport and better adapt existing modes to move people in more environmentally sound, efficient, and economically feasible ways. Bicycle sharing is evolving rapidly to fit the needs of the 21st century."

Although the BSS is very attractive as an alternative form of transportation, the major challenge is its economic viability. It is difficult for a BSS operator to turn a profit based on revenues collected on bicycle rides, as stated in Shu et al. in 2013 (see [14), where they mention that none of the existing BSSs in operation have produced a profit, and most BSSs rely on government subsidies. Actually, only 65 out of the 128 Spanish BSSs are still active. Thus, although the first BSS was founded in 1965, and these are now spread around the globe, studies of the design and management of BSSs are scarce and only began recently: DeMaio in 2003 and 2009 (see 4 and [5) or Lathia et al. in 2012 (8).

On the other hand, public bicycle share systems (PBSS) have also seen a sharp increase in the last decade, as described by Shaheen et al. (13]), and are currently an important part of public policy to obtain emission reductions, reduce congestion and fuel use and support for multimodal transport connections.

As an emerging area within the transportation research field, literature on PBSS is also limited. Within this area, the repositioning problem, to ensure the availability of bicycles and locks in the stations, has become the focus of attention. Kaltenbrunner et al. ([6]) analysed the result of a consumer satisfaction study for the PBSS in Barcelona which showed the two biggest problems detected and which cause user frustration and affect feasibility: the problem of finding a bike when a user wanted to start their journey, and the problem of leaving the bike at the user's destination due to empty or full stations respectively. This is a

35 general problem in all the PBSS, and draws a lot of attention to the problem of improving the redistribution of bikes from full to empty stations. So, Kaltenbrunner used data sampled from the operator's website to detect temporal and geographic mobility patterns within the city. These patterns are applied to predict the number of available bikes for any station in any time horizon. Contardo et al. ([3]) studied balancing a dynamic public bike-sharing system using Danzig-Wolf decomposition and Benders decomposition. Lin and

40 Yang (9) studied strategic design of public bicycle sharing systems with service level constraints, but without consideration on rebalancing bicycles. Later, Lin et al. (10]) added penalty costs about uncovered demand when considering the number and locations of bicycle sharing stations in the system. Sayarshad et al. ([12]) formulated the function maximizing the total benefit to company for the repositioning problem. Raviv et al. ([1] ) studied the static repositioning in a bike-sharing system and proposed a penalty function representing 45 the expected number of shortages, including loading and unloading times within a time constrained setting. They minimized the total cost of the system using mixed integer linear programming (MILP).

However, there are still knowledge gaps concerning who uses PBSS, what mode of transport would have been used if not using the PBSS, and whether trips generated would not have otherwise occurred, or the positive indirect effect in the economy and society as, for example, promoting the use of bicycles or

${ }_{50}$ improving the health of the users, some of which are studied in this paper. More specifically, three of the most important Spanish PBSS are analysed in this paper using their historical data on operating cost, rates, number of bicycles, demand, docks, etc. These data are projected in order to get their expected internal return rate for a time horizon of 20 years (2007-2026).

The rest of the paper is organized as follows. Section 2 presents a benchmarking of Spanish bike-sharing 55 systems, and Section 3 provides the methodology used and some general features about their feasibility. Finally, Section 4 presents the internal return rate obtained for the three Spanish systems analysed, while Section 5 summarizes the paper and discusses future work.

\section{Benchmarking of Spanish Public Bike Systems}

Below we shall present the main data compiled by Esther Anaya and Alberto Castro for "Observatorio so de la bicicleta pública en España" (visit [1]) in relation to:

1. Evolution and age of bike-sharing systems.

2. Evolution of number of bikes and stations of Spanish bike-sharing systems.

3. Population and impact of Spanish cities with a public bike system. 


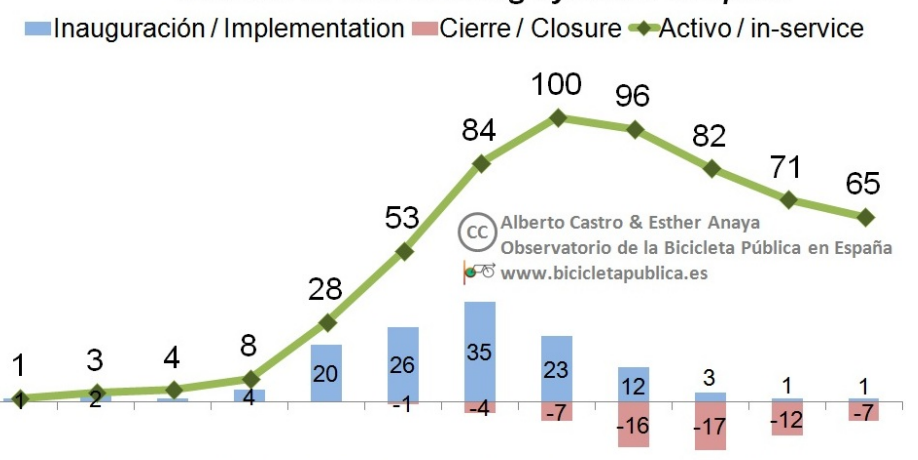

200320042005200620072008200920102011201220132014

Figure 1: Number of Spanish bike-sharing systems.

Source: "Observatorio de la bicicleta pública en España" 1

4. Analysis of supply levels in 3 Spanish systems (Barcelona, Valencia and Seville) and 6 foreign cities (Brussels, Dublin, Stockholm, Lille, London and Stuttgart).

\subsection{Number and age of bike-sharing systems}

As can be seen in Figure 1, there are currently 65 public bicycle systems operating in Spain. Therefore, from the first experience, in 2003, half of the 128 systems implemented have survived, with 2010 being the year in which the number of systems began to decrease. The greatest net reduction was registered in 2012. The decreasing trend began in 2010 and continues today. The possible causes of the closing of $50 \%$ of the public bicycle systems in the latter years could have been the excess of confidence in their introduction, the bad planning of the costs associated with the system and the economic crisis.

With respect to the age of these systems, in 2014 most of the public bicycle systems in operation had between 3 and 8 years of life (5.7 on average). With regard to the systems that have already disappeared, the majority lasted less than 4 years, with the average duration being 3 years. Note that more than $25 \%$ of the disappeared public bicycle systems closed in less than 2 years. These premature closures denote a possible lack of planning and previous evaluation of the project, especially if the causes of the closure were foreseeable (for example, maintenance costs or lack of actual resolve).

\subsection{Bikes and stations of bike-sharing systems}

Figure 2 shows that both the number of bicycles and stations have grown almost permanently, increasing from 5,000 bicycles and 800 stations in 2008, to 25,000 bicycles and 2,000 stations in 2014, in spite of the closure of $50 \%$ of the systems as previously commented. This is because the active systems increased their size considerably or the sizes of new systems were much greater than those that closed. In addition, the missing systems had an average of 6 stations, whereas the active systems have 32 . Therefore, it can be said

85 that, in Spain, a portfolio filled with small systems has changed to one more populated by those of medium size. As will be seen later, most of the closed systems belonged to small cities.

\subsection{Population and impact}

As shown again in [1, the municipalities of between 20,000 and 50,000 inhabitants have lodged the greater number of public bicycle systems in Spain. Nevertheless, the smaller the municipality, the lower

90 has been the probability of survival. At the present time, few public bicycle systems remain in small municipalities while most of them are in municipalities of between 50,001 and 100,000 inhabitants. These results confirm that the municipalities with less inhabitants have seen the most closures of public bicycle systems. Probably the economic crisis together with a lower budget in these municipalities has, in many cases, made the project economically unviable. In other cases what may have occurred is that the smaller 


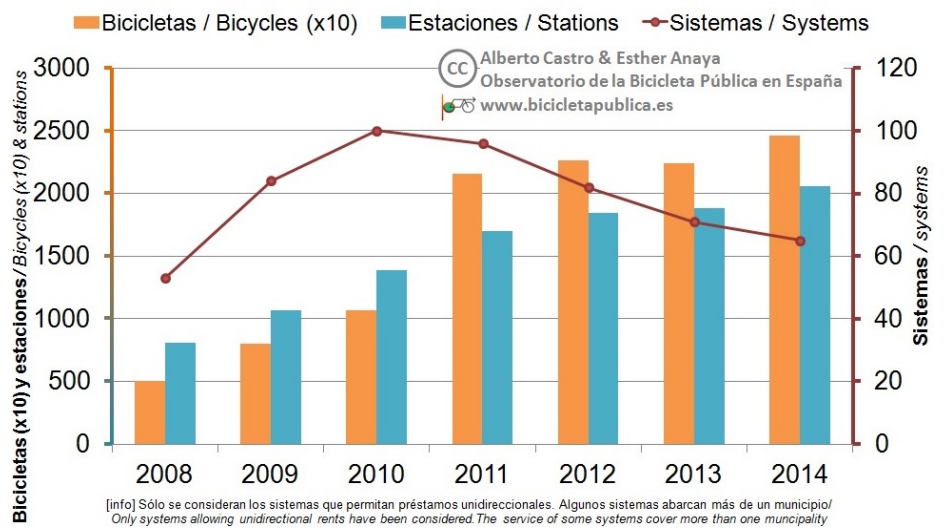

Figure 2: Number of bike-sharing bicycles and stations in Spain. Source: "Observatorio de la bicicleta pública en España" [1]

\begin{tabular}{c||cc} 
City & Stations $/ \mathrm{km} 2$ & Bicycles $/ \mathrm{km} 2$ \\
\hline Seville & 1.84 & 18.44 \\
Valencia & 2.04 & 20.43 \\
Barcelona & 4.20 & 58.88 \\
\hline Brussels & 2.63 & 31.90 \\
Dublin & 0.89 & 13.04 \\
Stockholm & 0.53 & 10.64 \\
Lille & 2.31 & 25.31 \\
London & 0.36 & 5.09 \\
Stuttgart & 0.31 & 1.93
\end{tabular}

Table 1: Comparison between the three selected Spanish systems and other 6 European cities.

To reliably measure the impact that a public bicycle system has in a municipality, and to make use of the available data, the authors chose to compare the number of daily loans per 1,000 inhabitants, getting the greater impacts in Barcelona, Valencia and Seville. For this reason, these are the three cities that were analysed in detail in the next sections.

\subsection{Supply Analysis}

Finally, the three selected Spanish systems (Barcelona, Valencia and Seville) are compared against 6 other representative European cities. In Table 1 stations and bicycles per square kilometre show elevated densities in the cities of Barcelona, Brussels, Lille, Valencia and Seville, both in terms of the number of stations as well as bicycles per square kilometre:

\section{General considerations on the viability. Methodology}

Analysing the financial viability of a public bicycle system is a complex task involving different factors, all of which are interdependent. Tariffs, number of bicycles, infrastructure and the number of subscribers are clearly linked, but other macroeconomic factors (such as the present context of economic crisis) may also negatively affect the number of subscribers and, for example, the income through publicity.

In short, and focusing on the main case of the financial viability of a public bicycle system, it can be concluded that the profitability depends on the following 6 factors (obviously they are not independent and the variations in some affect the others): 3 factors controlled by the Administration or the managing company and another 3 , more uncertain, external factors. The equation that relates them is: 


$$
\begin{gathered}
\text { Profits }=\text { Income }- \text { Expenses }= \\
=(\text { Num.Subscribers }) * \text { Tarif } f+\text { Publicity }-(\text { Num.Bicycles }) * \text { Cost } / \text { Bike }
\end{gathered}
$$

Those controlled by the Administration, usually agreed with the private concessionaire that manages the system, are:

1. Rates. The tariffs of the public bicycle systems are complex to accommodate the variety of users of these systems. However, the tariff by annual subscription is undoubtedly the most determinant because it represents most of the income for this factor.

2. Size of the system. Another key factor in determining the viability of the system is the number of bicycles. From the point of view of the user, the more bicycles the better. On the contrary, from the point of view of the manager, the more bicycles the greater are the operation and maintenance costs. Therefore it is important to find a balance in this factor.

3. Subsidies. The systems in Seville (Sevici) and in Valencia (Valenbisi), are managed by JCDecaux in exchange for a temporary assignment of various advertising spaces. When a public bicycle system is put out to tender, it is key to determine and agree the number of advertising elements. If a high number of spaces are offered, the concessionaire will obtain a high profit with which to manage the system, whereas if few spaces are ceded, losses can easily be made, increasing the tensions between both parties. In the case of Barcelona (Vodafone-Bicing), the City Council of Barcelona manages the publicity and subsidises the system to balance the annual accounts of Vodafone-Bicing.

The uncertain external factors are:

1. Subscribers. As will be seen later, the subscribers to these bicycle systems contribute approximately $33 \%$ of the income, which is why these systems are unviable without them. Also, the number of subscribers depends to a great extent on the tariff to be paid, as well as on other factors relating to the quality of the system (bicycle tracks, availability of bicycles, maintenance).

2. Operating and maintenance cost. This it is undoubtedly the most important factor of all, and also the most difficult to estimate. The managers of Vodafone-Bicing are the only ones that have published values for this cost, approaching 2,700 euros/year/bicycle (see [7]). In this study, starting with the hypothesis that the three analysed systems are viable, we will conclude that the annual cost per bicycle is around $2,000 €$.

3. Advertising revenue. This is another important factor of which some maximum values are known since JCDecaux published its tariffs on its Web page. The present context of economic crisis has caused a remarkable reduction in income through this factor.

Next, other important data on various Spanish public bicycle systems will be presented to understand them as determining behaviour patterns that help to model them, to analyse them and to eliminate as much uncertainty from their data as possible. Thus, the conditions will be determined that must occur to help the managers to respond to the classic questions that arise when it is desired to implement a system:

1. How many citizens will use the new system? How many subscribers are needed to guarantee profitability?

2. How will we charge for bicycle usage? What tariff is most appropriate?

3. How many bicycles will we install?

4. How many advertising spaces will be made available, if applicable?

The first data shown in Table 2 are: Name of the city (City column) and its name (System Name column), population (Population column), number of bicycles and stations (NBikes and NStat columns, respectively), annual rate in euros (AR column) and subscribers in 2014 (Subs. column). From all this it follows a common value for Seville and Barcelona (6\% approx.) regarding the percentage of annual subscribers with respect to the population, see Table 3 . Similar values also appear for Castellón and Zaragoza. 


\begin{tabular}{c|c|rrrrr} 
City & System Name & Population & NBikes & NStat & AR $(€)$ & Subs. \\
\hline Seville & Sevici & 700,000 & 2,600 & 265 & 39,00 & 42,000 \\
Barcelona & Vodafone-Bicing & $1,621,000$ & 6,000 & 428 & 47.16 & 100,000 \\
Valencia & Valenbisi & 800,000 & 2,750 & 275 & 27.12 & 87,000 \\
\hline Málaga & Malagabici & 568,500 & 200 & 10 & 5.00 & 15,000 \\
Santander & Tusbic & 178,500 & 200 & 15 & 25.14 & 2,600 \\
Castellón & BiciCas & 180,000 & 298 & 50 & 29.04 & 15,000 \\
A Coruña & Bicicoruña & 246,000 & 190 & 19 & 30.00 & 3,000 \\
Burgos & BiciBUr & 180,000 & 180 & 20 & 15.00 & 1,100 \\
Bilbao & BilbonBIZI & 351,000 & 200 & 25 & 15.00 & 10,300 \\
Zaragoza & Bizi & 680,000 & 260 & 130 & 37.00 & 39,000
\end{tabular}

Table 2: Key parameters of the main bicycle systems in Spain.

\begin{tabular}{c|c|rrr} 
City & System Name & Population & Subs. & Subs. (\%) \\
\hline Seville & Sevici & 700,000 & 42,000 & 6.00 \\
Barcelona & Vodafone-Bicing & $1,621,000$ & 97,000 & 5.98 \\
Valencia & Valenbisi & 800,000 & 87,000 & 10.88 \\
\hline Málaga & Malagabici & 568,500 & 15,000 & 2.64 \\
Santander & Tusbic & 178,500 & 2,600 & 1.46 \\
Castellón & BiciCas & 180,000 & 15,000 & 8.33 \\
A Coruña & Bicicoruña & 246,000 & 3,000 & 1.22 \\
Burgos & BiciBUr & 180,000 & 1,100 & 0.61 \\
Bilbao & BilbonBIZI & 351,000 & 10,300 & 2.93 \\
Zaragoza & Bizi & 680,000 & 39,000 & 5.74
\end{tabular}

Table 3: Percentage of subscribers in 2013 with respect to the total of citizens. 


\begin{tabular}{c|c|rrrrr} 
City & System Name & Population & AR & Subs. & Income & Inc/Pop \\
\hline Seville & Sevici & 700,000 & 39.00 & 42,000 & $1,638,000$ & 2.3400 \\
Barcelona & Vodafone-Bicing & $1,621,000$ & 47.16 & 97,000 & $4,574,520$ & 2.8220 \\
Valencia & Valenbisi & 800,000 & 27.12 & 87,000 & $2,359,440$ & 2.9493 \\
\hline Málaga & Malagabici & 568,500 & 5.00 & 15,000 & 75,000 & 0.1319 \\
Santander & Tusbic & 178,500 & 25.14 & 2,600 & 65,364 & 0.3662 \\
Castellón & BiciCas & 180,000 & 29.04 & 15,000 & 435,600 & 2.4200 \\
A Coruña & Bicicoruña & 246,000 & 30.00 & 3,000 & 90,000 & 0.3659 \\
Burgos & BiciBUr & 180,000 & 15.00 & 1,100 & 16,500 & 0.0917 \\
Bilbao & BilbonBIZI & 351,000 & 15.00 & 10,300 & 154,500 & 0.4402 \\
Zaragoza & Bizi & 680,000 & 37.00 & 39,000 & $1,443,000$ & 2.1221
\end{tabular}

Table 4: Income per inhabitant in 2013.

\begin{tabular}{c|c|rrr} 
City & System Name & Population & NBikes & Pop/NBikes \\
\hline Seville & Sevici & 700,000 & 2,600 & 269.23 \\
Barcelona & Vodafone-Bicing & $1,621,000$ & 6,000 & 270.17 \\
Valencia & Valenbisi & 800,000 & 2,750 & 290.91 \\
\hline Málaga & Malagabici & 568,500 & 200 & $2,842.50$ \\
Santander & Tusbic & 178,500 & 200 & 892.50 \\
Castellón & BiciCas & 180,000 & 298 & 604.03 \\
A Coruña & Bicicoruña & 246,000 & 190 & 1294.74 \\
Burgos & BiciBUr & 180,000 & 180 & $1,000.00$ \\
Bilbao & BilbonBIZI & 351,000 & 200 & $1,755.00$ \\
Zaragoza & Bizi & 680,000 & 260 & $2,615.38$
\end{tabular}

Table 5: Ratio of inhabitants per bicycle for various national systems.

However, this $6 \%$ value is not common to all the cities, as the number of subscribers also depends on the annual tariff of the system (which can explain $10.88 \%$ in Valencia whose annual tariff is only $27.12 €$, clearly inferior to Seville and Barcelona). Therefore, we calculated the income by subscribers and inhabitants (column Inc/Pop in Table 4). This calculation obtains the most stable pattern for the analysed cases. Values in the range of $2 €-3 €$ per inhabitant are repeated in those cases of success. Since the values nearest $2 €$ are given in the cities with a clear reduction of subscribers in recent months and whose profitability is low, we will henceforth suppose a value of $2.5 €$ as the minimum value to guarantee the viability of these systems. Later we will simulate the profitability of the systems of Seville, Valencia and Barcelona under this hypothesis.

As mentioned previously, finding a balance in the number of bicycles per inhabitant is fundamental due to the associated high cost of maintenance. Table 5 again shows a very stable value: 300 inhabitants for each bicycle (see Pop/NBikes columns).

The two last values used to make or simulate a comparative between Seville, Valencia and Barcelona are:

- Operating and maintenance cost. After analysing the cases of Seville, Valencia and Barcelona, the official data published by Vodafone-Bicing ([7]) and various meetings held with JCDecaux, we considered the cost of operation, maintenance and amortisation to be 2,000€ per bicycle per year. When we later assume that the managers want an average annual profitability of $10 \%$, the value of $2,200 €$ will be taken.

- Advertising revenue. According to data provided by JCDecaux in its Web page, and taking into account that generally $50 \%$ of the advertising spaces are ceded to the Administration, income for each billboard is estimated at $160 €$ per week. In the case of Vodafone-Bicing (Barcelona), we will use the equivalent of the subvention received in 2011 (11 million euros). 


\begin{tabular}{c|rrr} 
City & Population & Inc/Pop & Expected Inc $(€)$ \\
\hline Barcelona & $1,621,000$ & 2.5 & $4,052,500$ \\
Seville & 700,000 & 2.5 & $1,750,000$ \\
Valencia & 800,000 & 2.5 & $2,000,000$
\end{tabular}

Table 6: Expected income from Seville, Valencia and Barcelona at the ratio of $2.5 €$ per inhabitant.

\begin{tabular}{c|rrr} 
City & Expected Inc $(€)$ & Cost/Bike & Max. NBikes \\
\hline Barcelona & $4,052,500$ & 2,000 & 2,026 \\
Seville & $1,750,000$ & 2,000 & 875 \\
Valencia & $2,000,000$ & 2,000 & 1,000
\end{tabular}

Table 7: Bicycles that were hoped to be able to be maintained with the expected income.

Taking into account the previous parameters, the following comparison is obtained for the three systems. €.).

The main conclusion obtained from these simulations is that unifying the key parameters that determine the systems (bicycles, advertising spaces and inhabitants) that model the profitability, both the systems of Valencia (Valenbisi) and Barcelona (Vodafone-Bicing) generate high expected profitability, whereas the system of Seville (Sevici) is slightly above $6 \%$ profitability.

Moreover, if the rental volume in 2013 is taken into account, we obtain the following ratios of contribution per trip made. Table 11 shows the cost for the user (Subs. Cost column) and for the Administration (AdCost column) per trip made. Consequently, it is estimated that under the hypothesis of equity in income per inhabitants $(2.5 €$ per inhabitant), the unit cost per trip will rise to $0.68 €, 1.24 €$ and $0.61 €$ for Seville, Barcelona and Valencia, respectively. Taking into account what both contribute (user and Administration), these successful systems present similar proportions in the ratios per trip made close to $1 / 3$ by the users and $2 / 3$ by the Administration (whether by ceding advertising space or by means of subventions). In the following section, these values will be compared with the actual data collected from the three systems.

\section{Financial feasibility of the Spanish BSS}

Once the comparison of the three public bicycle systems is made under a hypothesis of equity and average efficiency, that is, under the hypothesis that all of them collect the same ratio of euros per inhabitant, they

\begin{tabular}{c|rrr} 
City & Max. NBikes & Current bikes & Shortage \\
\hline Barcelona & 2,026 & 6,000 & $-7,947,500 €$ \\
Seville & 875 & 2,600 & $-3,450,000 €$ \\
Valencia & 1,000 & 2,750 & $-3,500,000 €$
\end{tabular}

Table 8: Expected shortage for Seville, Valencia and Barcelona. 


\begin{tabular}{c|rrr} 
City & Shortage & Income/AdSpace & Min. AdSpace \\
\hline Barcelona & $-7,947,500 €$ & 160 & 955.2 \\
Seville & $-3,50,000 €$ & 160 & 414.7 \\
Valencia & $-3,500,000 €$ & 160 & 420.7
\end{tabular}

Table 9: Number of advertising spaces necessary to balance the generated deficit.

\begin{tabular}{c|rrrr} 
City & Min. AdSpace & Current AdSpace & Profit & Profit (\%) \\
\hline Barcelona & 955,2 & $1,560^{*}$ & $5,031,700 €$ & 29.54 \\
Seville & 414,7 & 460 & $377,200 €$ & 6.76 \\
Valencia & 420,7 & 600 & $1,492,000 €$ & 21.34
\end{tabular}

Table 10: Estimated profit for Seville, Valencia and Barcelona under the considered hypotheses

\subsection{Number of subscribers}

With respect to the number of subscribers, Table 12 shows the actual evolution of the number of subscribers (2007-2014) and estimated econometric linear regression models (2015-2027). These estimations are corrected in those anomalous cases under the following supposition. It is well-known, and as is happening in most of the public bicycle systems in Spain, that after reaching high levels of subscribers in 2011 and 2012, both the shift from public to private bicycle usage and the present crisis, have caused reductions in the number of subscribers of about 20\%. Also, this reduction could be explained by the increase of the tariffs. We will suppose that the actual subscriber number becomes stabilised and in the next few years will be increased slightly by around $1 \%$ per annum.

\subsection{Annual tariff}

The evolution of the annual tariff for the period 2007-2027 presents less uncertainty. In the case of the Seville system, these tariffs were decided with JCDecaux and the Planning Department of Seville Council at $62.50 €$ per annum in 2027. For Valencia and Barcelona they have been updated considering a Consumer Price Index (CPI) of $3 \%$ (see Table 13 ):

\subsection{Number of bicycles}

As can be seen in Table 14, there are only slight variations in the analysed period, these systems having arrived at the desired number that they considered optimal. It should be remembered that the value of 300 inhabitants per bicycle was previously proposed as most appropriate.

\subsection{Income through publicity and other aids}

The systems of Seville (Sevici) and Valencia (Valenbisi) are both managed by JCDecaux in exchange for the assignment of 460 and 600 advertising spaces, respectively (in addition to other smaller spaces). In the previous section, a weekly average income through advertising spaces of $160 €$ was considered. Again, this value is updated considering a CPI of $3 \%$. In the case of Barcelona (Vodafone-Bicing), this has received different subventions from Barcelona Council. The 15.5 million $€, 13.1$ million $€$ and 13 million $€$ received in 2009, 2010 and 2011, respectively, are highlighted. These figures are used next to estimate a financial profitability of these three systems.

\begin{tabular}{c|c|rrrrr} 
City & System Name & Num.Trips & Subs.Cost & AdCost & Subs.Cost $(\%)$ & AdCost $(\%)$ \\
\hline Seville & Sevici & $4,200,000$ & $0.23 €$ & $0.45 €$ & 33.77 & 66.23 \\
Barcelona & Vodafone-Bicing & $17,821,000$ & $0.42 €$ & $0.82 €$ & 33.65 & 66.35 \\
Valencia & Valenbisi & $9,000,000$ & $0.22 €$ & $0.39 €$ & 36.36 & 63.64
\end{tabular}

Table 11: Uniform comparison of the contributions per trip for users and Administration in 2013. 


\begin{tabular}{r|rrr} 
Year & Seville & Valencia & Barcelona \\
\hline 2007 & 9,250 & - & 102,146 \\
2008 & 38,338 & - & 156,079 \\
2009 & 53,929 & - & 139,670 \\
2010 & 44,861 & 40,000 & 117,523 \\
2011 & 47,910 & 50,000 & 121,819 \\
2012 & 49,907 & 110,000 & 113,787 \\
2013 & 42,842 & 92,000 & 99,403 \\
2014 & 48,022 & 87,000 & 97,109 \\
\hline 2015 & 48,467 & 85,000 & 101,401 \\
2016 & 48,898 & 82,000 & 102,415 \\
2017 & 49,319 & 82,000 & 103,439 \\
2018 & 49,733 & 80,000 & 104,474 \\
2019 & 50,140 & 80,000 & 105,518 \\
2020 & 50,542 & 85,000 & 106,573 \\
2021 & 50,941 & 85,000 & 107,639 \\
2022 & 51,336 & 85,000 & 108,716 \\
2023 & 51,729 & 85,000 & 109,803 \\
2024 & 52,120 & 90,000 & 110,901 \\
2025 & 52,510 & 90,000 & 112,010 \\
2026 & 52,899 & 90,000 & 113,130 \\
2027 & 53,288 & 90,000 & 114,261
\end{tabular}

Table 12: Evolution of the number of subscribers for the analysed systems.

\begin{tabular}{r|rrr} 
Year & Seville & Valencia & Barcelona \\
\hline 2007 & 10.00 & - & 24.00 \\
2008 & 10.00 & - & 24.00 \\
2009 & 10.00 & - & 30.00 \\
2010 & 10.00 & 18.00 & 30.00 \\
2011 & 25.00 & 18.00 & 30.00 \\
2012 & 27.50 & 18.00 & 44.00 \\
2013 & 30.76 & 24.00 & 45.11 \\
2014 & 39.33 & 27.12 & 47.16 \\
\hline 2015 & 40.95 & 28.20 & 48.57 \\
2016 & 42.45 & 29.33 & 50.03 \\
2017 & 43.95 & 30.51 & 51.53 \\
2018 & 45.50 & 31.73 & 53.08 \\
2019 & 47.15 & 33.00 & 54.67 \\
2020 & 48.85 & 34.32 & 56.31 \\
2021 & 50.60 & 35.69 & 58.00 \\
2022 & 52.40 & 37.12 & 59.74 \\
2023 & 54.30 & 38.60 & 61.53 \\
2024 & 56.25 & 40.14 & 63.38 \\
2025 & 58.25 & 41.75 & 65.28 \\
2026 & 60.33 & 43.42 & 67.24 \\
2027 & 62.50 & 45.16 & 69.26
\end{tabular}

Table 13: Evolution of the annual tariff for the analysed systems. 


\begin{tabular}{r|rrr} 
Year & Seville & Valencia & Barcelona \\
\hline 2007 & 1,500 & - & 3,000 \\
2008 & 1,500 & - & 6,000 \\
2009 & 1,500 & - & 6,000 \\
2010 & 2,500 & 500 & 6,000 \\
2011 & 2,500 & 2,700 & 6,000 \\
2012 & 2,600 & 2,750 & 6,000 \\
2013 & 2,600 & 2,750 & 6,000 \\
2014 & 2,600 & 2,750 & 6,000 \\
\hline 2015 & 2,600 & 2,750 & 6,000 \\
2016 & 2,650 & 2,750 & 6,000 \\
2017 & 2,700 & 2,750 & 6,000 \\
2018 & 2,750 & 2,750 & 6,000 \\
2019 & 2,800 & 2,800 & 6,000 \\
2020 & 2,800 & 2,800 & 6,000 \\
2021 & 2,800 & 2,800 & 6,000 \\
2022 & 2,800 & 2,800 & 6,000 \\
2023 & 2,800 & 2,800 & 6,000 \\
2024 & 2,800 & 2,800 & 6,000 \\
2025 & 2,800 & 2,800 & 6,000 \\
2026 & 2,800 & 2,800 & 6,000 \\
2027 & 2,800 & 2,800 & 6,000
\end{tabular}

Table 14: Evolution of the number of bicycles for the analysed systems.

\begin{tabular}{c|c} 
Annual Cost & IRR (\%) \\
\hline 2,000 & $32.49 \%$ \\
2,100 & $15.64 \%$ \\
2,200 & $6.72 \%$ \\
2,300 & $0.00 \%$
\end{tabular}

Table 15: Evolution of the IRR according to annual costs of the bicycles for Sevici.

\subsection{Annual cost per bicycle}

As mentioned previously, an annual cost of maintenance and amortisation of the initial investment of $2,000 €$ per bicycle is estimated, without considering the profitability of the systems. If it is required to incorporate, for example, a profitability of $10 \%$ of this cost, a cost per bicycle of $2,200 €$ could be supposed.

\subsection{Feasibility}

The Internal Rate of Return (IRR) was estimated for the three analysed systems: Seville (Sevici), Valencia (Valenbisi) and Barcelona (Vodafone-Bicing). In addition, we analysed the sensitivity of the internal return rate to the most important parameter: the cost of operations and maintenance.

\subsubsection{Seville-Sevici}

According to the evolution of the previous parameters, the public bicycle system in Seville (Sevici), displays an IRR of $6.72 \%$, slightly superior to the $6 \%$ that is commonly considered as the minimum level of profitability. This value coincides with the one simulated in the above section (see Table 10). Moreover, Table 15 shows the sensitivity of the IRR to the annual cost per bicycle. 


\begin{tabular}{c|c} 
Annual Cost & IRR (\%) \\
\hline 2,100 & $104.37 \%$ \\
2,200 & $64.04 \%$ \\
2,300 & $41.69 \%$ \\
2,400 & $28.25 \%$
\end{tabular}

Table 16: Evolution of the IRR according to annual costs of the bicycles for Valenbisi.

\begin{tabular}{c|ccc} 
Year & 2009 & 2010 & 2011 \\
\hline IRR (\%) & $43.09 \%$ & $24.04 \%$ & $23.48 \%$
\end{tabular}

Table 17: Vodafone-Bicing returns for 2009-2011.

\subsubsection{Valencia-Valenbisi}

The case of Valencia (see Table 16 ) is remarkable in that, in spite of its similarities with Seville (in inhabitants and number of bicycles), it presents great differences consisting of: greater number of subscribers and more advertising spaces ceded. For all that, it is a good example to compare with Seville. In this case, the IRR obtained for Valenbisi is $64.04 \%$ for a cost of $2,200 €$.

\subsubsection{Barcelona-Vodafone-Bicing}

In this case it is not possible to calculate the IRR due to the system of financing of the system by means of subventions. What has been able to be estimated, according to the costs declared by the managers of Vodafone-Bicing themselves, is an annual profitability for the period 2009-2011. These returns are $23 \%-43 \%$, as indicated in Table 17

\subsection{Unit cost}

In order to conclude with the results section, it is of great interest for the managers and administrators of public transport to be able to compare the unit cost per trip made.

\subsubsection{Seville-Sevici}

The unit cost per trip for the system implemented in Seville was estimated to be $1.20 €$ at the end of 2014, $0.44 €$ being contributed by the user and $0.76 €$ by the Administration (by means of the assignment of advertising space). This distribution represents proportions of $37 \%-63 \%$. The unit cost and the proportions are expected to evolve as shown in Figure 3

\subsubsection{Valencia-Valenbisi}

With respect to the system of Valencia, the unit cost per trip is $1.55 €$, with $0.57 €$ contributed by the user and $0.98 €$ by the Administration. This distribution represents proportions of $36.7 \%-63.3 \%$ The unit cost and the proportions are expected to evolve as shown in Figure 4 .
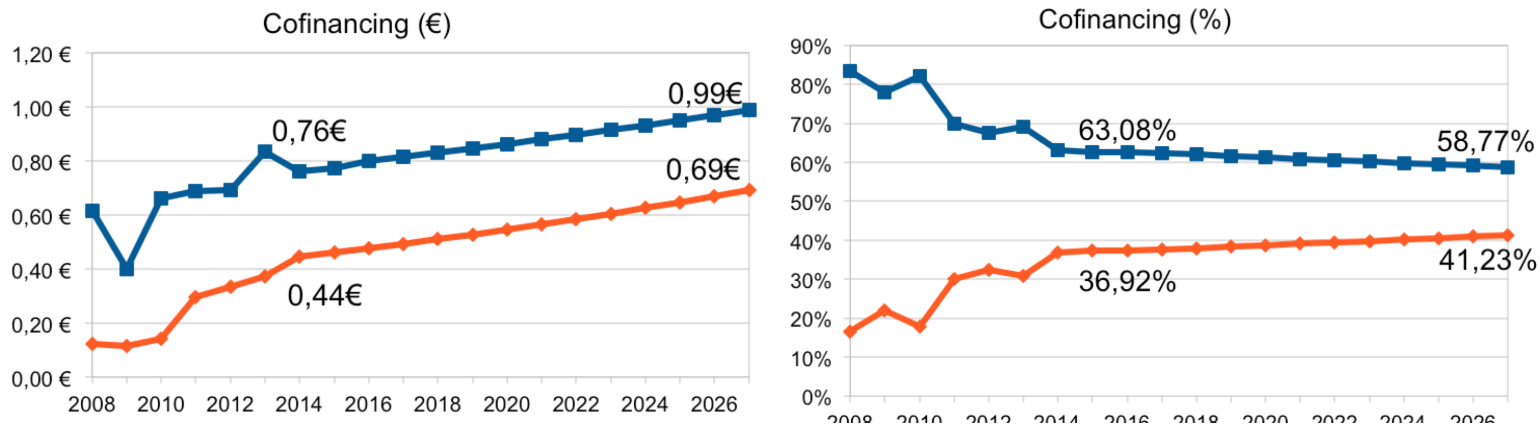

Figure 3: Cost per journey for Seville (Seville). 

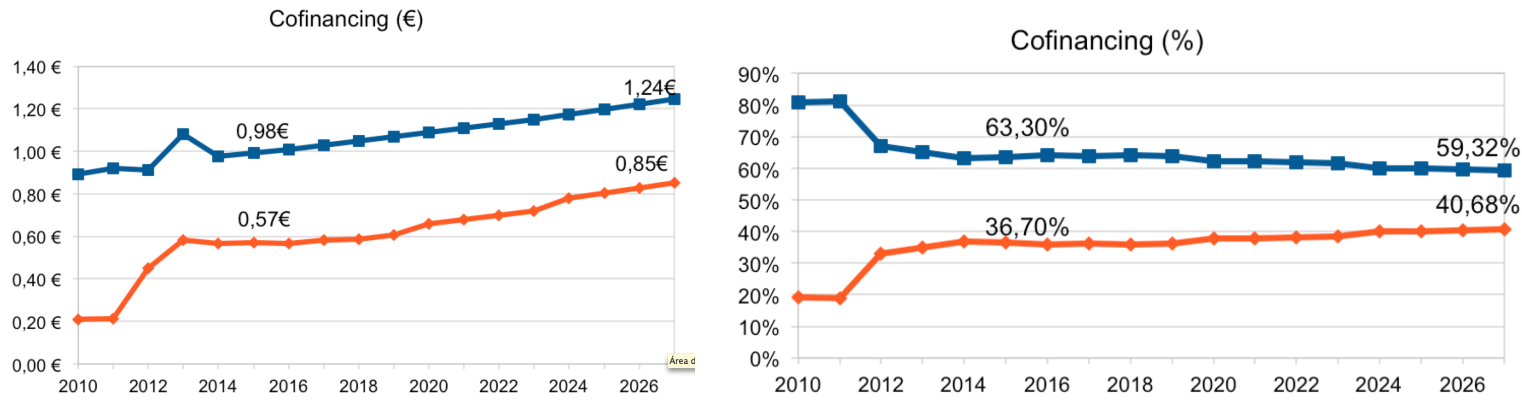

Figure 4: Mi Figura
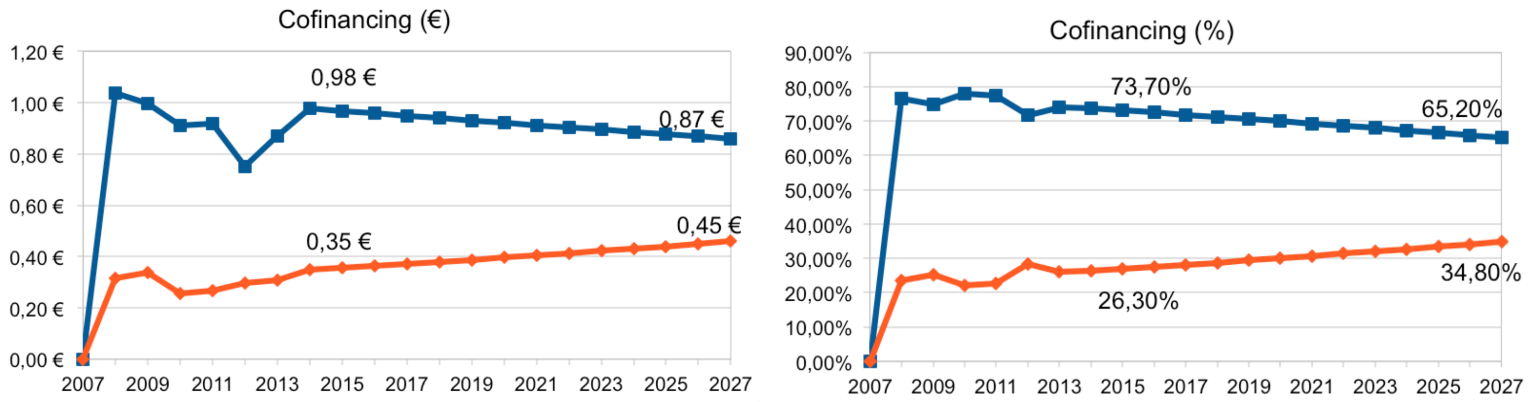

Figure 5: Mi Figura

\subsubsection{Barcelona-Vodafone-Bicing}

The unit cost per trip for the Vodafone-Bicing system is $1.33 €$, with $0.35 €$ contributed by the user and $0.98 €$ by the Administration. This distribution represents proportions of $26.3 \%-73.7 \%$. The unit cost and

the proportions are expected to evolve as shown in Figure 5

\section{Conclusions}

The implementation of public bicycle rental schemes has rapidly become widespread in Spain since the year 2004, following the success of the pilot programme in Vitoria-Gasteiz, one of the first cities to incorporate the bicycle into the public transport system, both in a comprehensive and intermodal sense. This has led to a large amount of controversy as, in the 75 systems implemented in Spanish cities, few have had a clear repercussion on mobility. Some said these were very good, others that they were very expensive. However, we could not find any scientific studies that rigorously evaluated how good or how expensive. For those reasons we decided to fill this gap, and struggling against the lack of openness, along with the support of a team of concerned experts and friends, we carried out a quantitative evaluation through the use of common transport analysis tools. Some interesting conclusions were reached in the case of the public bicycle rental scheme in Seville and Valencia which, along with that in place in Barcelona, are the systems that have had the greatest repercussion in terms of mobility (these cases can be deemed a success).

The main results we obtained were twofold: The first is the detection of several hidden patterns/parameters associated with the viability of public bike-sharing systems in Spain. Thus, the Internal Return Rate is calculated for the three major systems: Seville (Sevici), Valencia (Valenbisi) and Barcelona (Vodafone-Bicing). The second is of an economic nature, and shows that the balance between the cost involved with each journey by bicycle and the provision of funds by the Public Sector Administration (understood in the case of Seville as the contribution provided through the concession of the development of advertising spaces, a different model to that used in Barcelona) is similar to the aforesaid balance in the urban transport network 
managed by bus operators. As the bicycle is a healthier and non-polluting means of transport, it purports to have a major added value.

\section{Acknowledgment}

The authors would like to thank the FEDER of European Union for financial support via Project Impacto de la Bicicleta Pblica en Andaluca (GGI3001IDIW) of the Programa Operativo FEDER de Andaluca 20072013. We also thank all Agency of Public Works and the Ministry of Furtherance and Housing of Andalusia Regional Government staff and researchers for their dedication and professionalism.

[1] Anaya, E. Castro, A., Observatorio Público de la Bicicleta en España, website: http : //bicicletapublica.es.

[2] B:SM (2012), BICING, Un modelo de éxito, Ajuntament de Barcelona, http : //bcnmobilitat.itt.upc.edu/documents/pdf/_IFHP/bcn/18 - 04 - bicing.pdf .

300 [3] Contardo, C., Morency, C., Rousseau, L. M. (2012) Balancing a Dynamic Public Bike-Sharing System, 4, CIRRELT.

[4] DeMaio P. (2003), Smart bicycles: Public transportation for the 21st century. Transportation Quart. 57(1):9-11.

[5] DeMaio P. (2009), Bicycle-sharing: History, impacts, models of provision, and future. J. Public Transportation 12(4):41-56.

[6] Kaltenbrunner, A., Meza, R., Grivolla, J., Codina, J., Banchs, R. (2010), Urban cycles and mobility patterns: Exploring and predicting trends in a bicycle-based public transport system. Pervasive and Mobile Computing 6 (2010) 455-466.

[7] B:SM (2012),BICING, Un modelo de éxito, Ajuntaments //bcnmobilitat.itt.upc.edu/documents/pdf / ${ }_{I} F H P / b c n / 18-04-$ bicing.pdf.

[8] Lathia N, Ahmed S, Capra L (2012) Measuring the impact of opening the London shared bicycle scheme to casual users. Transportation Res. Part C 22:88?102.

[9] Lin, J. R., Yang, T. H. (2011) Strategic Design of Public Bicycle Sharing Systems with Service Level Constraints, Transportation Research Part E: Logistics and Transportation Review, 47, 284-294.

[10] Lin, J. R., Yang, T. H., Chang, Y. C. (2013) A hub location inventory model for bicycle sharing system design: Formulation and solution, Computers \& Industrial Engineering, 65(1), 77-86.

[11] Raviv, T., Tzur, M., Forma, I. A. (2013) Static Repositioning in a Bike-Sharing Systems: Models and Solution Approaches, EURO Journal on Transportation and Logistics, 1-43.

[12] Sayarshad, H., Tavassoli, S., Zhao, F. (2012) A multi-periodic optimization formulation for bike planning and bike utilization, Applied Mathematical Modelling, 36(10), 4944-4951.

[13] Shaheen, S., Guzman, S., Zhang, H. (2010). Bikesharing in Europe, the Americas, and Asia. Transportation Research Record: Journal of the Transportation Research Board, 2143, 159?167.

[14] Shu J., Chou M, Liu O., Teo C., Wand I, (2013): Models for Bicycle-Sharing Systems. Operations Research 61(6), pp. $1346 ? 1359$. 